\title{
HUBUNGAN BEBAN KERJA DENGAN KINERJA PERAWAT DALAM MENGIMPLEMENTASIKAN PATIENT SAFETY DI RUMAH SAKIT STELLA MARIS MAKASSAR
}

\author{
RELATIONSHIP BETWEEN WORK LOADS AND \\ NURSING PERFORMANCE IN IMPLEMENTING \\ SAFETY PATIENT IN STELLA MARIS MAKASSAR \\ HOSPITAL
}

\author{
Euis Dedeh Komariah ${ }^{1}$, Nikodemus Sili Beda ${ }^{2}$, Elni Anggriani ${ }^{3}$, Bettoen Talumba Feramita \\ Keperawatan, STIK Stella Maris Makassar
}

\begin{abstract}
Patient safety in a hospital is often associated with work loads problem due to lack of available staff / nurses. The purpose of this study was to determine the workload and its relationship with work achievement of nurses at Stella Maris Hospital Makassar. The research design used was an observational analytic with cross-sectional. The sample size were 80 respondents with probability sampling techniques using random sampling. The instrument used was a questionnaire. The results of the study obtained that 59 respondents (73.8\%) worked more and as many as 62 (77.6\%) had good performance. From the results of the chi square test obtained $p$ value $=0.004$, which showed the value of $p<\alpha$ that is $\alpha=$ 0.05 so that the alternative hypothesis (Ha) was accepted and the null hypothesis (Ho) was rejected. So, there was correlation between workload and nursing performance in implementing the Patient Safety at Stella Maris Hospital Makassar. Then it can be concluded that nurses have a longer workload.
\end{abstract}

Keywords $\quad$ : Workload, Performance of Patient Safety

\begin{abstract}
ABSTRAK
Keselamatan pasien di Rumah Sakit adalah suatu sistem dimana masalah yang mempengaruhi kinerja yaitu beban kerja yang tidak sesuai dengan staf/perawat yang tersedia. Tujaun dari penelitian ini adalah untuk mengetahui hubungan beban kerja dengan kinerja perawat dalam mengimplementasikan patien safety di Rumah Sakit Stella Maris Makassar. Desai penelitian yang digunakan adalah observasional analitik dengan pendekatan cross sectional study. Besar sampel adalah 80 responden dengan teknik probability sampling dengan pendekatan simple random sampling. Instrument yang digunakan adalah kuesioner. Hasil penelitian yang didapatkan sebanyak 59 responden $(73,8 \%)$ yang beban kerja lebih dan sebanyak $62(77,6 \%)$ yang memiliki kinerja baik. Dari hasil uji chi square di peroleh nilai $\mathrm{p}=0,004$, yang menunjukkan nilai $\mathrm{p}<\alpha$ yaitu $\alpha=0,05$ sehingga hipotesis alternative (Ha) diterima dan hipotesis nol (Ho) ditolak. Artinya ada
\end{abstract}


BMJ. Vol 6 No 2, 2019: 173-183

DOI: https://doi.org/10.36376/bmj.v6i2

hubungan beban kerja dengan kinerja dalam mengimplementasikan patient safety di Rumah Sakit Stella Maris Makassar. Maka dapat disimpulkan bahwa perawat yang memiliki beban kerja lebih tidak selamanya berpengaruh kepada kinerja perawat yang kurang.

Kata Kunci : Beban kerja, kinerja patient safety

\begin{tabular}{ll}
\hline Alamat Korespondensi & $\begin{array}{l}\text { : Jl. Maipa No.19, Losari, Kec. Ujung Pandang, Kota Makassar, } \\
\text { Sulawesi Selatan. }\end{array}$ \\
Email & euisspup@gmail.com
\end{tabular}

\section{PENDAHULUAN}

Keselamatan (safety) telah menjadi isu global untuk rumah sakit. Ada lima isu penting terkait dengan keselamatan di rumah sakit yaitu keselamatan pasien (patient safety), keselamatan pekerja atau tugas kesehatan, keselamatan bangunan dan peralatan di rumah sakit yang dapat berdampak terhadap keselamatan pasien dan petugas, keselamatan lingkungan, keselamatan bisnis rumah sakit yang terkait dengan kelangsungan hidup Rumah Sakit Kemenkes RI (2015).

Memberikan mutu pelayanan kesehatan yang optimal, Rumah Sakit memerlukan tenaga-tenaga kesehatan yang produktif dalam bekerja. Tenagatenaga kesehatan tersebut yakni dokter, perawat, bidan, apoteker, fisioterapi dan tenaga kesehatan lainnya (Fatimah, 2012, dalam Satriani Wa, 2013).

Namun, ada satu masalah yang mempengaruhi kinerja perawat yaitu beban kerja yang tidak sesuai dengan staf/perawat yang tersedia. Perawat melaksanakan pelayanan 24 jam dalam tujuh hari langsung kepada pasien, keberagaman dan kerutinan pelayanan tersebut apa bila tidak dikelola dengan baik bisa saja menyebabkan kejadian tidak diharapkan (KTD) dengan kejadian nyaris cedera (KNC).

WHO (2014) di Eropa angka kejadian resiko infeksi 83,5\% dan bukti kesalahan medis menunjukkan 50-72,3\%. Dikumpulkan angka-angka penelitian di rumah sakit di berbagai negara, ditemukan Kejadian Tidak Diharapkan (KTD) dengan rentang 3,2-16,6\%

Sementara itu di New York, Kejadian Tidak Diharapkan (KTD) adalah sebesar 3,7 \% dengan angka kematian 13,6\%. Angka akibat KTD pada pasien rawat inap di seluruh Amerika yang berjumlah 33,3 juta pertahun berkisar 44.000-98.000 pertahun (Ismainar,2012). KKP-RS (Komite Keselamatan Pasien Rumah Sakit) melaporkan insiden keselamatan pasien sebanyak 145 insiden yang terdiri dari KTD 46\%, KNC (Kejadian Nyaris Cidera) 48\% dan lain-lain 6\% dan lokasi kejadian tersebut berdasarkan provinsi ditemukan di DKI Jakarta menempati urutan tertinggi yaitu 37, 9\%, Jawa Tengah 15,9\%, di Yogyakarta 13,8\%, Jawa Timur $11,7 \%$, Sumatera Selatan 6,9\%, Jawa Barat 2,8\%, Bali 1,4\%, Sulawesi Selatan $0,69 \%$, dan Aceh $0,68 \%$. Kesalahan dalam pemberian obat menduduki peringkat pertama $(24,8 \%)$ dari sepuluh besar insiden yang dilaporkan (Handayanidkk., 2014).

Menurut (Agency For Health Care Research and Quality (AHRQ) (2003, dalam Mulyati 2001) menyatakan bahwa KTD biasa terjadi dikarenakan oleh 
DOI: https://doi.org/10.36376/bmj.v6i2

beberapa masalah yakni masalah sumber daya manusia, kebijakan dan prosedur yang tidak adekuat dan factor yang berpengaruh dalam resiko terjadinya infeksi di rumah sakit salah satunya yaitu beban kerja yang tidak sesuai dengan staf/perawat yang tersedia.

Di Rumah Sakit Stella Maris ditemukan selama tiga tahun terakhir, sejak tahun 2015-2017 terdapat beberapa unit yaitu laboratorium, loket, farmasi, ruang perawatan, kamar operasi dan dokter.Tahun 2015 terdapat 6 kasus KTD, 8 kasus KNC, dan 5 kasus KTC. Pada tahun 2016 terdapat 3 kasus KTD, 9 kasus KNC, 7 kasus KTC, dan 1 kasus sentinel sedangkan tahun 2017 terdapat 5 kasus KTD, 5 kasus KNC, dan 4 kasus KTC.

Dari hasil observasi didapatkan bahwa salah satu pemicu dari kejadian tidak diharapkan yang terjadi, adalah akibat dari beban kerja perawat yang tinggi dan menyebabkan tingkat komunikasi antar perawat berkurang, dan menurut wawancara pada salah satu perawat didapatkan informasi bahwa beban kerja perawat di Rumah Sakit Stella Maris Makassar tinggi, dikarenakan jumlah tenaga perawat yang kurang memadai atau tidak mencukupi untuk jumlah pasien, jumlah perawat di salah satu ruang perawatan di Stella Maris hanya terdapat 12 perawat dan 2 diantaranya merangkap tugas, dan kadang dalam melaksanakan asuhan keperawatan tidak berpedoman pada SOP yang ada dengan alas an karena adanya keterbatasan tenaga, alat, dan bahan yang tersedia.

Berdasarkan penelitian yang dilakukan oleh Retananingsih Dwi (2016, dengan judul "Beban kerja perawata terhadap implementasi patient safety di ruang rawat inap". Ada hubungan beban kerja perawat terhadap implementasi di ruang rawat inap di RSUD Tugerejo Semarang.

Sementara itu, penelitian yang dilakukan oleh Elizabeth (2013), dengan judul“" Hubungan beban kerja dengan kinerja perawat dalam pemberian asuhan keperawatan di instalasi rawat inap". Ada hubungan beban kerja dengan kinerja perawat dalam pemberian asuhan keperawatan.

Berdasarkan uraian di atas peneliti ingin mengetahui "Hubungan beban kerja dengan kinerja perawat dalam mengimplementasikan patient safety di Rumah Sakit Stella Maris Makassar".

\section{METODE PENELITIAN}

Penelitian ini menggunakan desain observasional analitik yang bertujuan untuk mengetahui hubngan beban kerja perawat dengan kinerja perawat dalam mengimplementasikan patient safety di Rumah Sakit Stella Maris. Jenis Penelitian ini adalah pendekatan cross sectional. Penelitian ini dilaksanakan mulai 22 Januari sampai 2 Februari 2019. Populasi dalam penelitian ini adalah perawat pelaksana dengan teknik pengambilan sampel probability sampling dengan pendekatan simple randomsampling dengan jumlah sampel 80 responden dengan kriteria inklusi perawat pelaksana yang berada di ruang rawat inap yang telah terpapar penerapan tentang sasaran keselamatan pasien dan perawat yang berada di tempat saat penelitian serta bersedia menjadi responden, serta kriteria ekslusi adalah Kepala ruangan dan perawat pelaksana yang cuti. Instrumen dalam penelitian ini menggunakan kuesioner secara langsung kepada responden. Pengumpulan data dilakukan dengan prosedur yaitu mendapat rekomendasi dari pihak institusi 
DOI: https://doi.org/10.36376/bmj.v6i2

Sekolah Tinggi Ilmu Kesehatan (STIK) Stella Maris Makassar kemudian mengajukan permohonan izin kepada instansi tempat penelitian yaitu Rumah Sakit Stella Maris Makassar. Sementara itu, pengolahan data dilakukan dengan proses editing, coding, dan tabulating. Dalam menganalisis data menggunakan SPSS versi 21 windows dengan uji statistic chi-square.

\section{HASIL}

\section{HASIL DAN PEMBAHASAN}

1. Penyajian Karakteristik Data Umum

Data yang menyangkut karakteristik responden akan diuraikan sebagai berikut:

a. Berdasarkan Karakteristik Umur

Tabel 5.1.Distribusi Frekuensi Responden Berdasarkan Umur Perawat di Rumah Sakit Stella Maris Makassar

\begin{tabular}{ccc}
\hline Umur (thn) & Frekuensi (f) & Presentase (\%) \\
\hline $\mathbf{2 3 - 2 9}$ & 43 & 53.8 \\
$\mathbf{3 0 - 3 6}$ & 25 & 31.3 \\
$\mathbf{3 7 - 4 3}$ & 10 & 12.5 \\
Thtal $^{\mathbf{4 3}}$ & 2 & 2.5 \\
Tht & 80 & 100 \\
\hline
\end{tabular}

Sumber: data primer 2019

Dari hasil penelitian berdasarkan umur perawat diperoleh data responden dengan umur 23-29 tahun 43 responden (53,8\%), 30-36 tahun 25 responden $(31,3 \%), 37-43$ tahun 10 responden $(12,5 \%)$ dan umur $>43$ yaitu 2 responden $(2,5 \%)$.

b. Berdasarkan Karakteristik Jenis Kelamin

Tabel 5.2. Distribusi Frekuensi Responden Berdasarkan Jenis Kelamin Perawat di Rumah Sakit Stella Maris Makassar 2019

\begin{tabular}{ccc}
\hline Jenis Kelamin & Frekuensi (f) & Presentase (\%) \\
\hline Laki-laki & 6 & 7.5 \\
permpuan & 74 & 92.5
\end{tabular}

\begin{tabular}{lrr} 
Total & 80 & 100 \\
\hline Sumber: data primer 2019 &
\end{tabular}

Dari hasil penelitian berdasarkan jenis kelamin perawat diperoleh data responden dengan jenis kelamin laki-laki berjumlah 6 responden $(7,5 \%)$ dan jenis kelamin perempuan yaitu berjumlah 74 responden $(92,5 \%)$. 
c. Berdasarkan Karakteristik Pendidikan

Tabel 5.3. Distribusi Frekuensi Responden Berdasarkan Pendidikan Perawat di Rumah Sakit Stella Maris Makassar 2019

\begin{tabular}{ccc}
\hline Pendidikan & Frekuensi (f) & Presentase (\%) \\
\hline D3 & 54 & 67.5 \\
S1 & 7 & 8.8 \\
Ners & 19 & 23.8 \\
Total & 80 & 100 \\
\hline
\end{tabular}

Sumber: data primer 2019

Dari hasil penelitian berdasarkan pendidikan perawat diperoleh data responden yaitu perawat dengan pendidikan D3 berjumlah 54 responden $(67,5 \%)$, perawat dengan pendidikan $\mathrm{S} 1$ berjumlah 7 responden $(8,8 \%)$ dan perawat dengan pendidikan Ner berjumlah 19 responden $(23,8 \%)$.

d. Berdasarkan Karakteristik Lama Masa Kerja

Tabel 5.4. Distribusi Frekuensi Responden Berdasarkan Lama Masa Kerja Perawat di Rumah Sakit Stella Maris Makassar 2019

\begin{tabular}{ccc}
\hline $\begin{array}{c}\text { Lama Masa } \\
\text { Kerja (thn) }\end{array}$ & Frekuensi (f) & Presentase (\%) \\
\hline $\mathbf{1 - 7}$ & & \\
$\mathbf{8 - 1 4}$ & 62 & 77.5 \\
$\mathbf{1 5 - 2 3}$ & 13 & 16.3 \\
$\mathbf{> 2 3}$ & 2 & 2.5 \\
Total & 3 & 3.8 \\
\hline
\end{tabular}

Sumber: data primer 2019

Dari hasil penelitian berdasarkan lama masa kerja perawat diperoleh data 1-7 tahun 62 responden (77,5\%), 8-14 tahun 13 responden (16,3\%), 1523 tahun 2 responden $(2,5 \%)$ dan $>23$ tahun yaitu 3 responden $(3,8 \%)$.

e. Berdasarkan Karakteristik Shif Kerja

Tabel 5.5. Distribusi Frekuensi Responden Berdasarkan Shift

Kerja Perawat di Rumah Sakit Stella Maris Makassar 2019

\begin{tabular}{ccc}
\hline Shift Kerja & Frekuensi (f) & Presentase (\%) \\
\hline Pagi & 43 & 53.8 \\
Sore & 23 & 28.8 \\
Malam & 14 & 17.5 \\
Total & 80 & 100 \\
\hline
\end{tabular}

Sumber: data primer 2019

Dari hasil penelitian berdasarkan shift kerja perawat diperoleh data shift pagi 43 responden $(53,8 \%)$, shift sore 23 responden $(28,8 \%)$ dan shift malam 14 responden $(17,5 \%)$. 
BMJ. Vol 6 No 2, 2019: 173-183

ISSN : 2615-7047

DOI: https://doi.org/10.36376/bmj.v6i2

2. Hasil Analisa Variabel Yang Diteliti

a. Analisa Univariat

1) Beban kerja

Tabel 5.6. Distribusi Frekuensi Berdasarkan Beban Kerja Perawat di

Rumah Sakit Stella Maris Makassar 2019

\begin{tabular}{lll}
\hline Beban & Frekuensi (f) & Presentase(\%) \\
Kerja &
\end{tabular}

\begin{tabular}{lll}
\hline Lebih & 59 & 77.8 \\
\hline Kurang & 21 & 22.2 \\
& & \\
\hline Total & 80 & 100 \\
\hline \multicolumn{2}{l}{ Sumber: } & data primer 2019
\end{tabular}

Dari hasil penelitian berdasarkan beban kerja perawat diperoleh data beban kerja perawat lebih 59 responden $(77,8 \%)$, dan beban kerja perawat kurang 21 responden $(22,2 \%)$.

2) Kinerja Perawat

Tabel 5.7. Distribusi Frekuensi Berdasarkan Kinerja

Perawat di Rumah Sakit Stella Maris Makassar 2019

\begin{tabular}{lll}
\hline $\begin{array}{l}\text { Kinerja } \\
\text { Perawat }\end{array}$ & Frekuensi (f) & $\begin{array}{l}\text { Presentase } \\
(\%)\end{array}$ \\
\hline Baik & 62 & 77.5 \\
\hline Kurang & 18 & 22.5 \\
\hline Total & 80 & 100
\end{tabular}

Sumber: data primer 2019

Dari hasil penelitian berdasarkan kinerja perawat diperoleh data kinerja perawat baik sebanyak 62 responden $(77,5 \%)$, dan kinerja perawat kurang baik 18 responden $(22,5 \%)$.

b. Analisis Bivariat

Tabel 5.8. Hubungan Beban Kerja dengan Kinerja Perawat Dalam Mengimplementasikan Patient Safety di Rumah Sakit Stella Maris Makassar 2019

\begin{tabular}{|c|c|c|c|c|c|c|c|}
\hline \multirow{2}{*}{$\begin{array}{l}\text { Beban } \\
\text { Kerja } \\
\end{array}$} & \multicolumn{4}{|c|}{ Kinerja Perawat } & \multirow[t]{2}{*}{ Total } & \multirow{2}{*}{\multicolumn{2}{|c|}{$\mathbf{p}$}} \\
\hline & Bai & & & & & & \\
\hline & $\mathrm{f}$ & $\%$ & $\mathrm{f}$ & $\%$ & $\mathrm{n}$ & $\%$ & \\
\hline Lebih & 51 & 63.8 & 8 & 10.0 & 59 & 73.8 & 0.004 \\
\hline Kurang & 11 & 13.8 & 10 & 12.5 & 21 & 26.3 & \\
\hline Total & 62 & 77.5 & 18 & 22.5 & 80 & 100 & \\
\hline
\end{tabular}

Balimedikajurnal.com 
Dari hasil penelitian berdasarkan beban kerja dan kinerja perawat dalam mengimplementasikan pasient safety diperoleh data beban kerja lebih kinerja perawat baik yaitu 51 responden $(63,8 \%)$. Sedangkan beban kerja lebih dan kinerja kurang baik yaitu 8 responden (10.0\%). Untuk beban kerja kurang dan kinerja baik 11 responden $(13,8 \%)$, sedangkan beban kerja kurang tetapi kinerja perawat kurang baik 10 responden (12,5\%).

Dari hasil statistic menggunakan uji statistic chi square dengan nilai kemaknaan $\alpha=0,05$ sehingga didapatkan $\mathrm{p}$ value $=$ 0,004 (Continuity Correction) hal ini menunjukkan bahwa nilai $\mathrm{p}<$ 0,05 , maka artinya ada hubungan beban kerja dengan kinerja perawat dalam mengimplementasikan pasient safety di Rumah Sakit Stella Maris Makassar.

\section{PEMBAHASAN}

Berdasarkan hasil penelitian yang dilakukan di Rumah Sakit Stella Maris Makassar didapatkan bahwa dari hasil uji statistic menggunakan uji chi squeare dengan nilai kemaknaan $\alpha=0,05$ diperoleh nilai $\mathrm{p}=0,004$ (Continuity Correction) artinya ada hubungan beban kerja dengan kinerja perawat dalam mengimplementasikan patient safety di Rumah Sakit Stella Maris Makassar, walaupun beban kerja perawat lebih tetapi tetap memberikan kinerja yang baik.

Menurut Munandar (2011), mengatakan bahwa beban kerja memiliki 2 macam, yaitu beban kerja kuantitatif dan beban kerja kualitatif. Dimana beban kuantitatif merupakan rasio perawat dan pasien, banyaknya pekerjaan yang harus dilakukan oleh seseorang, dan beban kerja kualitatif adalah tingkat kesulitan atau kerumitan dalam kerja.

Menurut Ratanto (2013) yang mengatakan faktor internal yang memengaruhi kinerja perawat baik diantaranya rata-rata umur responden berada pada usai produktif, lama kerja rata-rata kurang dari 4 tahun, sebagian pendidikan perawat pelaksana adalah vokasional, motivasi dan persepsi perawat pelaksana terhadap pekerjaannya baik.

Menurut asumsi peneliti perawat yang memiliki beban kerja lebih tetapi memberikan kinerja baik dalam mengimplementasikan patient safety karena faktor individu atau yang dimiliki perawat itu sendiri seperti keterampilan (skil), kemampuan, motivasi. Rata-rata lama masa kerja responden paling banyak adalah 1-7 tahun (tenaga kerja baru) yang berada pada usia 23-29 tahun (usia produktif) dan pada usia produktif tersebut memacu motivasi diantara perawat untuk menunjukkan kinerja yang baik, tenaga kerja baru dan muda merupakan tenaga kerja potensial, dan sebagian besar pendidikan perawat adalah vokasional atau perawat pelaksana. Oleh sebab itu kinerja perawat yang bekerja di Rumah Sakit Stella Maris dalam kategori baik dan harus dipertahankan supaya dapat dijadikan contoh buat perawat-perawat yang lain untuk terus meningkatkan kinerja dan memberikan asuhan keperawatan yang berkualitas.

Hasil peneliti menunjukkan bahwa beban kerja perawat lebih dan kinerja perawat baik dalam mengimplementasikan patient safety di Rumah Sakit Stella Maris Makassar yaitu sebanyak 51 responden $(63,8 \%)$. Hal ini sejalan dengan 
penelitian Astriana, et all (2014) bahwa ada hubungan signifikan antara beban kerja dengan kinerja perawat dalam penerapan program keselamatan pasien. Menurut Nikolaus (2016) ada 5 faktor yang mempengaruhi kinerja baik yaitu, factor personal atau individu, faktor kepemimpinan, faktor tim, faktor sistem, faktor kontekstual atau situasonal. Asumsi peneliti bahwa perawat yang memiliki beban kerja lebih dengan kinerja baik, karena disebabkan motivasi yang tinggi dari perawat dan kerja keras dalam menjalankan tanggung jawabnya, serta hal tersebut juga tidak luput dari pengawasan kepala ruangan dan tuntutan dari pihak Rumah Sakit yang mengharuskan perawat atau staf rumah sakit untuk selalu memberikan asuhan keperawatan yang berkualitas sesuai dengan visi dan misi rumah sakit. Walaupun beban kerja yang lebih di Instalasi Rawat Inap RS Stella Maris Makassar tetapi perawat masih menunjukkan kinerja yang baik dan ini membuktikan bahwa perawat di RS. Dapat bekerja dengan baik sesuai dengan standar dalam mengimplementasikan patient safety.

Berdasarkan hasil penelitian yang dilakukan oleh peneliti didapatkan beban kerja perawat lebih dan kinerja perawat kurang baik dalam mengimplementasikan patient safety di Rumah Sakit Stella Maris Makassar yaitu sebanyak 8 responden $(10,0 \%)$. Hal ini sejalan dengan penelitian Retraningsih (2016), menunjukan bahwa terdapat hubungan beban kerja perawat dalam mengimplementasikan patient safety, dimana hasil penelitiannya menunjukkan bahwa beban kerja perawat yang berat berpengaruh pada implementasi patient safety yang kurang baik karena adanya perbedaan jumlah kegiatan atau aktivitas pada shift kerja, jumlah pasien, jumlah perawat serta perbedaan kelas perawatan. Menurut Wibowo (2013) pengukuran terhadap kinerja perlu dilakukan untuk mengetahui apakah selama pelaksanaan kinerja terhadap deviasi dari rencana yang telah ditentukan, atau apakah kinerja dapat dilakukan sesuai jadwal waktu yang diharapkan. Menurut asumsi peneliti bahwa apa bila beban kerja perawat lebih maka berdampak pada kinerja perawat yang kurang baik karena dipengaruhi oleh efek yakni kelelahan yang dialami oleh perawat karena tuntutan kerja yang diembankan kepada perawat tersebut terlalu tinggi sehingga secara otomatis kinerja perawat dalam mengimplementasikan patient safety juga dapat terganggu serta dapat mempengaruhi hasil kerja perawat tersebut kurang.

Berdasarkan hasil penelitian yang dilakukan oleh peneliti didapatkan beban kerja dengan kinerja perawat dalam mengimplementasikan patient safety di Rumah Sakit Stella Maris Makassar dalam kategori beban kerja kurang dan kinerja baik yaitu sebanyak 11 responden (13,8\%). Hal ini sejalan dengan penelitian Elizabeth (2015) berdasarkan hasil yang telah didapatkan menunjukkan sebagian besar $(89,9 \%)$ perawat memiliki beban kerja rendah dengan kinerja yang baik. Menurut Manuba (2000 dalam Prihatini, 2007) ada 2 hal yang mempengaruhi kondisi tersebut yaitu faktor eksternal dan faktor internal. Menurut asumsi perawat faktor eksternal dari penelitian ini yaitu karena adanya keseimbangan jumlah perawat dan jumlah pasien, lingkungan fisik yang nyaman, kerja sama yang terjalin baik antara sesama perawat dan tuntutan dari pihak Rumah Sakit untuk selalu memberikan pelayanan keperawatan yang baik serta supervisi dari kepala ruangan membuat perawat terus meningkatkan mutu pelayanan keperawatan. Sedangkan faktor internal atau kondisi perawat itu sendiri yaitu kemampuan yang tinggi dan kerja keras dari perawat dalam menjalankan tanggung jawabnya. 
Hasil penelitian menunjukkan bahwa beban kerja kurang dan kinerja kurang yaitu 10 responden (12,5\%). Hal ini sejalan dengan penelitian Hidayah (2018), yang menyatakan bahwa ada hubungan beban kerja dengan kinerja perawat dalam mengimplementasikan patient safety, dimana hasil penelitiannya menunjukkan perawat yang memiliki beban kerja tidak berat dan kinerjanya dalam penerapan patient safety tidak baik sebanyak 17 orang responden $(58,6 \%)$ menurut Rivai (2009), kinerja adalah sesuatu yang dicapai, prestasi yang diperlihatkan dan kemampuan kerja. Kinerja dikatakan tinggi apabila suatu target kerja dapat diselesaikan pada waktu yang tepat atau tidak melampaui batas waktu yang disediakan sedangkan kinerja dikatakan rendah jika diselesaikan melampaui batas waktu yang disediakan atau sama sekali tidak terselesaikan.

Menurut asumsi peneliti bahwa perawat yang memiliki beban kerja kurang dan kinerja kurang baik, dikarenakan rasa tanggung jawab yang kurang, dan tidak mampu menyelesaikan tugas yang diberikan dengan tepat waktu.

\section{SIMPULAN DAN SARAN}

\section{SIMPULAN}

Dari penelitian yang dilakukan terhadap 80 responden di Rumah Sakit Stella Maris Makassar yang di mulai tanggal 22 Januari - 02 Februari 2019, maka dapat disimpulkan bahwa: Beban kerja perawat dalam mengimplementasikan patient safety di Rumah Sakit Stella Maris Makassar sebagian besar pada kategori lebih, kinerja perawat dalam mengimplementasikan patient safety di Rumah Sakit Stella Maris dalam kategori baik, Ada hubungan beban kerja dengan kinerja perawat dalam mengimplementasikan patient safety di Rumah Sakit Stella Maris Makassar.

\section{SARAN}

1. Bagi Institusi Rumah Sakit

Hasil penelitian ini menunjukkan beban kerja yang dihadapi perawat pada kategori lebih maka dari itu untuk instalasi Rumah Sakit Stella Maris Makassar memperhatikan beban kerja yang di hadapi perawat agar tidak terus menerus mengalami beban kerja yang lebih sehingga tidak menimbulkan stress kerja yang bisa berdampak pada kinerja perawat, dengan menambahkan tenaga kerja, menambahkan alat dan bahan di Rumah Sakit maka perawat akan lebih memperhatikan SOP sehingga dapat mengurangi kesalahan-kesalahan saat bekerja dan perawat akan lebih memperhatikan keselamatan pasien.

2. Bagi Perawat

Diharapkan penelitian ini semakin meningkatkan mutu kinerja perawat dalam mengimplementasikan patient safety di Rumah Sakit.

3. Bagi Peneliti

Dapat menambah pengalaman, pengetahuan peneliti tentang hubungan beban kerja dengan kinerja perawat dalam mengimplementasikan patient safety.

4. Bagi Mahasiswa STIK Stella Maris

Penelitian ini diharapkan dapat menambah pengetahuan bagi mahasiswa tentang beban kerja perawat dan bagaimana kinerja perawat dalam mengimplementasikan patient safety di Rumah Sakit. 
BMJ. Vol 6 No 2, 2019: 173-183

ISSN : 2615-7047

DOI: https://doi.org/10.36376/bmj.v6i2

\section{DAFTAR PUSTAKA}

Astriani.(2014).Hubungan Pendidikan Masa Kerja dan Beban Kerja dengan Keselamatan Pasien RSUD Haji Makassar. Diakses 25 Februari 2019

DepkesRI . (2013). Panduan Keselamatan Pasien di Rumah Sakit. Jakarta. Salemba Medika.

Elizabeth,M.(2015). Hubungan Beban Kerja dengan Kinerja Perawat Dalam Pemberian Asuhan Keperawatan di Instalasi Rawat Inap RSUP Prof. DR.R.D Kandon Manado. Jurnal Keperawatan, volume 3, No 2. Diakses 27 Februari 2019.

Handayani,F.(2017).Gambaran Insiden Keselamatan Pasien Berdasarkan

Karakteristik Perawat, Organisasi, Dan Sifat Dasar Pekerjaan Di Unit Rawat Inap Rumah Sakit Al-Islam Bandung Pada Periode 2012-2016. Diakses 15 September 2018

Hidayah.(2018). Pengaruh Kepemimpinan Efektif Beban Kerja dan Motivasi Kerja Terhadap Kinerja Perawat Dalam Penerapa Patient Safety di Rumah Sakit PKU Muhammadiyah Bantul. Diakses 26 Februari 2019.

Ismainar, H, \& dkk.(2012). Efektivitas Kepemimpinan Dan Komunikasi Tim Keselamatan Pasien Di RSI Ibnu Sina Pekanbaru Riau.jurnal Kesehatan Komunitas, Volume II,No 1. Diakses 20 September 2019

Joint Commision International. (2011). Accreditation Stadar For Hospitals 4th Edition, Oak Brook.

KKPRS. (2011). Standar Pelayanan Rumah Sakit Institusi Penilaian

Akreditasi RS Pelayanan Intensif. Jakarta:PERSI.

Nasution. (2010). ManajemenMutuTerpadu Edisi 3. Jakarta: Ghlia Indonesia.

Nikolaus \& Kewuan. (2016). Manajemen Kinerja Keperawatan. Jakarta. EGC.

Nursalam. (2011).Manajemen Keperawatan Edisi 3. Jakarta.Salemba Medika

Nursalam. (2008).Konsep dan Penenrapan Metodologi Penelitian Ilmu Keperawatan Edisi 2. Jakarta. Salemba Medika.

Nursalam.(2015). Manajemen Keperawatan. Jakarta. Salemba Medika.

Nurjanah, S. (2017). Analisis Beban Kerja Tenaga Perawat di Instalasi Rawat Inap Rumah Sakit Umum Daerah (RSUD). Jurnal Ilmiah Mahasiswa Kesehatan Masyarakat, Volume II, No.5.

Notoadmojo.(2009).Pengembangan Sumber Daya Manusia. Cetakan 4.Jakarta : Rineka Cipta.

PPNI. (2010). Standar Praktik Keperawatan. Jakarta: PPNI.

Ratanto. (2013). Pengembangan Karier Sebagai Fakor Paling Memengaruhi Kinerja Perawat Pelaksanan. Jurnal Keperawatan Indonesia, Volume 16, No 2.

Retnaningsih, D, \&Fatimah,D. (2016). Beban Kerja Perawat Terhadap Implementasi Patient Safety Di Ruang Rawat Inap. Jurnal Keperawatan Soedirman, volume 11,No1. Diakses 15 September 2018

Rivai.(2009). Manajemen Sumber Daya Manusia Teori dan Praktek Edisi.2. Jakarta: Rajawali Press.

Saleng, M. (2015). Fakto Faktor Yang Berhubungan Dengan Kinerja Perawat Di Ruang Rawat Inap Rumah Sakit Khusus Daerah Provinsi Sulawesi Selatan. Diakses 1 November 2018

Balimedikajurnal.com 
DOI: https://doi.org/10.36376/bmj.v6i2

Simamora Roymond, H. (2014). Buku Ajar Manajemen Keperawatan. Jakarta. EGC.

Sugiono .(2013). Metode Penelitian Kuantitatif Kualitatif Dan R \& D. Bandung :Alvabeta

Sutraningsih, A.(2016). Penmgetahuan Perawat Tentang Keselamatan Pasien Dengan Pelaksanaan Prosedur Keselamatan Pasien Rumah Sakit (KPRS). Jurnal Care, Volume 3,No 1.Diakses 1 November 2018

Triwibowo,C, \& dkk.(2016). Handover Sebagai Upaya Peningkatan Keselamatan Pasien Di Rumah Sakit. Jurnal Keperawatan Soedirman, volume 11,No 2.Diakses 5 November 2018

Prihatini.(2007). Analisis Hubungan Beban Kerja Dengan Stres Kerja Perawat Di Tiap Ruang Rawat Inap RSUD Sidikalang Medan. Diakses 25 Februari 2019

Wibowo.(2013). Manajemen Kinerja.Edisi 3.Cet. 6.Jakarta :Rajawali Pers. 